\title{
Future local anaesthetics-neurotoxins?
}

\begin{abstract}
The currently available local anaesthetic agents are non-specific blockers of the sodium channel. Neurotoxins, derived from various sources are very potent, specific blockers of the voltage gated sodium channels. Their site of action is also quite different from the local anesthetics. The major toxic manifestation of neurotoxins is muscle paralysis, which is easier to manage as compared to the more serious cardiac and central nervous system effects of conventional local anesthetics. A brief mention of the currently relevant neurotoxins and the early studies are summarized.
\end{abstract}

Keywords: local anaesthetics, neurotoxins
Volume 2 Issue 6 - 2015

\author{
Prasanna Vadhanan,' Adhinarayanan ${ }^{2}$ \\ 'VMMCH, India \\ 2JIPMER, India
}

Correspondence: Prasanna Vadhanan, VMMCH, No 6, P\&T

Nagar Mayiladuthurai, Karikal, India 60900I, Tel +919486489690,

Email vadhanan.prasanna@gmail.com

Received: August 04, 2014 | Published: August 25, 2015
Abbreviations: DRG, dorsal root ganglia; VGSC or $\mathrm{Na}_{\mathrm{v}}$, voltage-gated sodium channels; STX, sax Toxin

\section{Introduction}

The use of cocaine by Keller in 1884 heralded a new class of drugs which would later prove indispensable in routine anesthesia practice. Lignocaine (1943) and bupivacaine (1963), the earliest of the local anesthetics quickly replaced cocaine and procaine because of their better safety profile. Even with the introduction of newer local anesthetics like ropivacaine and levobupivacaine, the search for the ideal local anaesthetic is still on.

\section{Ideal local anaesthetic}

Local anaesthetics act on sodium channels and block progression of nerve impulse. Sodium channels exist in several isoforms and are also present in several other tissues like in central nervous system, skeletal muscles and myocardium. At least nine distinct voltage-gated sodium channels (VGSC or $\mathrm{Na}_{\mathrm{v}}$ ) have been cloned from mammals, being broadly divided by its affinity to tetrodotoxin (a neurotoxin) $\mathrm{Na}_{\mathrm{v}} 1.1, \mathrm{Na}_{\mathrm{v}} 1.2, \mathrm{Na}_{\mathrm{v}} 1.3$, and $\mathrm{Na}_{\mathrm{v}} 1.7$ are highly tetrodotoxin-sensitive, whereas $\mathrm{Na}_{\mathrm{v}} 1.5, \mathrm{Na}_{\mathrm{v}} 1.8$, and $\mathrm{Na}_{\mathrm{v}} 1.9$ are tetrodotoxin-resistant to varying degrees. ${ }^{1}$

The nonspecific actions of local anesthetics are partly responsible for the systemic side effects.

The ideal local anaesthetic should possess the following properties
A. No systemic toxicity
B. Longer shelf life
C. Better sensory motor separation
D. Prolonged action
E. Stability
F. No tissue irritation
G. Easily metabolized

By the current know edge of $\mathrm{Na}_{\mathrm{v}}$ isoforms, it would be ideal for local anaesthetics to specifically block neuronal $\mathrm{Na}$ channels. The affinity of local anaesthetics for $\mathrm{Na}_{\mathrm{v}}$ channels is quite low. Low affinity clinically translates to more systemic toxicity.

\section{Neurotoxins}

Neurotoxins encompass aide group of drugs which acts on various ionic channels like sodium, potassium, calcium and chloride channels. Neurotoxins that bind to the voltage gated sodium channels (VGSC or $\mathrm{Na}_{\mathrm{v}}$ ) have gained much attention as local anaesthetics, and they bind to the outer pore of the $\mathrm{Na}_{\mathrm{v}}$ channel, unlike conventional local anesthetics. Initial use of neurotoxins was met with high incidence of toxicity in the form of diaphragmatic paralysis, but subsequent studies with lower doses shows promise.

\section{Key differences}

They differ from conventional local anaesthetics in these key aspects.

I. Neurotoxins have very high affinity for neuronal $\mathrm{Na}_{\mathrm{v}}$ channels as compared to local anaesthetics. The dissociation constants are in the range of $10^{-9}$ to $10^{-6} \mathrm{~mol} / \mathrm{L}$ (neurotoxins) as compared to $10^{-4}$ to $10^{-3} \mathrm{~mol} / \mathrm{L}$ (local anaesthetics). ${ }^{2}$

II. They are very specific to neuronal $\mathrm{Na}_{\mathrm{v}}$ channels, hence cardiac and neurological side effects are low. For example, The affinity of cardiac purkinjefibresto neurotoxin is 200 fold lesser than that of axons. ${ }^{3}$ Hence cardiac side effects should be lesser

III. They are extremely potent, hence need very small doses. At $\mathrm{pH}$ 7.2, $2 \mathrm{nM}$ neo-sax toxin produces $50 \%$ inhibition of compound action potentials in peripheral nerves. ${ }^{4}$ In other words, neo-sax toxin is roughly 1 million fold more potent than lidocaine.

IV. The site of action is different. While local anaesthetics inhibit sodium channel activity by binding to the inner pore entering from the intracellular side, the toxins bind to the outer pore of the channel. ${ }^{5}$

Also, the predominant toxic effect is diaphragmatic paralysis which responds to ventilator support, as opposed to more serious neurological and cardiovascular side effects of conventional local anaesthetics.

\section{Tetrodotoxin}

Tetrodotoxin is a naturally occurring neurotoxin of organisms belonging to the Tetradontidae order, which includes the puffer fish, ocean sunfish, and porcupine fish. They are specific blockers of $\mathrm{Na}$ channel, but differently from local anaesthetics. Tetrodotoxin is known to plug the $\mathrm{Na}+$ channel from the external side of the permeation pathway adjacent to the narrow selectivity filter region. ${ }^{6}$ When combined with adrenaline, it caused prolonged block of rat sciatic nerve. Considerable systemic toxicity precludes its clinical use. ${ }^{7}$ 


\section{Neo sax toxin(Neo STX)}

Among these agents, this one seems most promising. Sax toxin (STX) is a neurotoxin produced by certain species of din flagellates and cyanobacteria. Ingestion of sax toxin (usually through shellfish contaminated by toxic algal blooms) and is responsible for the human illness known as paralytic shell fish poisoning.

Neo sax toxin differs from sax toxin by the addition of an oxygen atom wherein the hydrogen $(-\mathrm{H})$ at nitrogen 1 of sax toxin is replaced by a hydroxyl (-OH) group. Neo STX has been shown to be more potent than sax toxin and tetrodotoxin both in vitro and in vivo. ${ }^{8,9}$

In a first ever study to assess the clinical efficacy of neo STX on human volunteers, 50micrograms of neo STX was injected subcutaneously on the skin of the calf and sensory parameters were assessed. All sensory modalities (warmth, cold, heat pain, cold pain, touch) were reliably abolished for an average of 3 hours. Return to baseline values took as long as 9 to 12 hours. ${ }^{10}$

Wound infiltration with neosaxitoxin after laparoscopic cholecystectomy provided lower pain scores after 12 hours as compared to bupivacaine, and no adverse events were more frequent in the neo STX group. ${ }^{11}$

Other such toxins which are of interest include ralfinamide, 5Arryl 2 furfurramides, ziconotide and pro TX II. A series of 6-aryl-2-pyrazinecarboxamides which are potent blockers of the human $\mathrm{Na}_{\mathrm{v}} 1.8$ channel also block TTx-r sodium currents in rat dorsal root ganglia (DRG) neurons. ${ }^{12}$

Pro TX II is a peptide from the venom of the tarantula Thrixopelmaprurien. It is primarily a sodium channel inhibitor, but it appears to act predominately on $\mathrm{C}$ nerve fibers, with little effect on a beta fibers. This selectivity may due to an action upon a novel binding site that is not occupied by traditional local anesthetics. ${ }^{13}$

Conotoxin represent a category of poisons produced by the marine cone snail (Genus- Conus), and are capable of inhibiting the activity of a number of ion channels such as calcium, sodium, or potassium channels. Ziconotide is a conotoxin that blocks neuronal calcium channels and operates at the spinal cord level. Prolonged intrathecal administration of ziconotide has been shown to be useful in chronic pain and does not cause addiction or tolerance. ${ }^{14}$ Side effects include nausea, dizziness, headache, confusion, somnolence, memory impairment and small increases in creatine kinase. ${ }^{15}$

\section{Conclusion}

Further studies are needed in establishing the dosage and side effects of these compounds. The selectivity, potency and safety profile of neurotoxins would soon make them the ideal local anaesthetic agents.

\section{Acknowledgements}

None.

\section{Conflicts of interest}

The authors declare that there are no conflicts of interest.

\section{Funding}

None.

\section{References}

1. Goldin AL, Barchi RL, Caldwell JH, et al. Nomenclature of voltagegated sodium channels. Neuron. 2000;28(2):365-368.

2. Butterworth JF. Will conventional local anaesthetics soon be replaced by neurotoxins? Reg Anesth Pain Med. 2011;36(2):101-102.

3. Baer M, Best PM, Reuter H. Voltage dependant action of tetrodotoxin in mammalian cardiac muscle. Nature. 1976;263(5575):344-345.

4. Strichartz G. Structural determinants of the affinity of saxitoxin for neuronal sodium channels. Electrophysiological studies on frog peripheral nerve. J Gen Physiol. 1984;84(2):281-305.

5. Kohane DS, Lu NT, Gokgol-Kline AC, et al. The local anaesthetic properties and toxicity of saxitoxin homologues for rat sciatic nerve block in vivo. Reg Anesth Pain Med. 200;25(1):52-59.

6. Wang GK, Srichartz GR. State dependent inhibition of sodium channels by local anaesthetics : A 40 year evolution. Biochem (Mosc) Suppl Ser A Membr Cell Biol. 2012;6(2):120-127.

7. Kohane DS, Yieh J, Lu NT, et al. A re-examination of tetrodotoxin for prolonged duration local anesthesia. Anesthesiology. 1998;89(1):119131

8. Kohane DS, Lu NT, Gokgol-Kline AC, et al. The local anaesthetic properties and toxicity of saxitoxin homologues for rat sciatic nerve block in vivo. Reg Anesth Pain Med. 2000;25(1):52-59.

9. Strichartz G, Rando T, Hall S, et al. On the mechanism by which saxitoxin binds to and blocks sodium channels. Ann N Y AcadSci. 1986;479:96-112.

10. Alberto J, Rodriguez- Navarro AJ, et al. Neo saxitoxin as a local anesthetic. Anesthesiology. 2007;106(2):339-345.

11. Rodríquez-Navarro AJ, Berde CB, et al. Comparison of neosaxitoxin versus bupivacaine via port infiltration for postoperative analgesia following laparoscopic cholecystectomy. A randomized double -blind controlled trial. Reagents Pain Med. 2011;36(2):103-109.

12. Scanio MJ, Shi L, Drizin I, et al. Discovery and biological evaluation of potent, selective, orally bioavailable, pyrazine-based blockers of the $\mathrm{Na}(\mathrm{v}) 1.8$ sodium channel with efficacy in a model of neuropathic pain. Bioorg Med Chem. 2010;18(22):7816-7825.

13. Schmalhofer W, Calhoun J, Burrows R, et al. ProTx-II a selective inhibitor of Na1.7 sodium channels, blocks action potential propagation in nociceptors. Molecular Pharmacology. 2008;74(5):1476-1484.

14. McGivern JG. Ziconotide A review of its pharmacology and use in the treatment of chronic pain. Neuropsychiatr Dis Treat. 2007;3(1):69-85.

15. Wallace MS, Rauck R, Fisher R, et al. Intrathecal ziconotide for severe chronic pain:safety and tolerability results of an open-label, long-term trial. Anaesthesia \& Analgesia. 2008;106(2):628-637. 